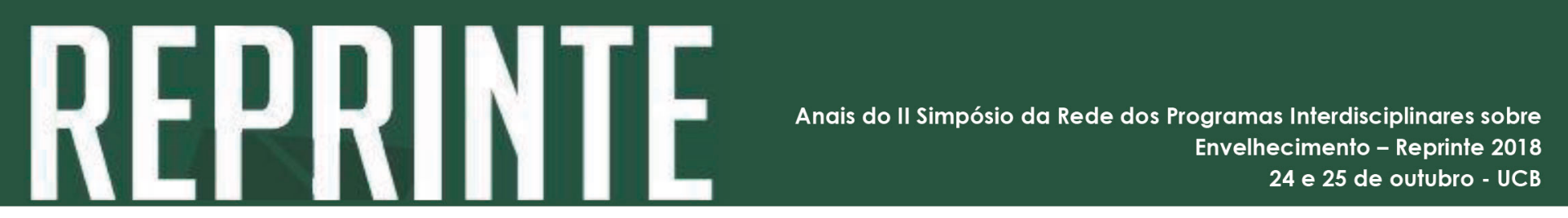

http://dx.doi.org/10.5335/rbceh.v16i1.9770

\title{
6) Desafios relacionados à avaliação do estresse oxidativo no processo de envelhecer
}

\author{
Agnaldo Bruno Chies ${ }^{1}$; Guilherme Costa Munhoz ${ }^{2}$; Priscilla Bianca de Oliveira²
}

\section{Resumo}

O estresse oxidativo é definido como uma condição fisiopatológica em que produção de espécies reativas excede a capacidade das defesas antioxidantes do organismo em removê-las. Avaliar o grau de estresse oxidativo é essencial para a compreensão de diversos processos fisiologicos que mantêm a homestasia nas diversas fases do ciclo da vida. Para isso, diversas técnicas simples e baratas podem ser empregadas. O presente trabalho propõe-se a apresentar algumas técnicas de estudo do estudo do estresse oxidativo, fazendo uma reflexão acerca de suas potencialidades e limitações. Pode se dizer que a credibilidade do estudo eleva-se pelo cuidado na padronização das técnicas, rigor do delineamento experimental e pela confirmação dos resultados através de diferentes técnicas, que avaliam diferentes processos que determinam o balanço redox.

Palavras-chaves: Defesas antioxidantes; Estresse oxidativo; Função endotelial; Peroxidação lipídica

\section{Avaliação do estresse oxidativo}

Poucas substâncias que interagem com os sistemas orgânicos têm um papel tão enigmático quanto aquelas que, coletivamente, denominam-se "espécies reativas". Espécies reativas são substâncias instáveis capazes de reagir com diferentes moléculas constituintes dos tecidos animais e vegetais. As espécies reativas podem ser de oxigênio (Ex: $\mathrm{O}_{2}^{\bullet} ; \mathrm{H}_{2} \mathrm{O}_{2} ; \mathrm{HO} \bullet$ ), de nitrogênio (Ex: $\mathrm{NO}^{\bullet} \mathrm{OONO}^{-}$), de enxofre $\left(\mathrm{Ex}\right.$ : $\left.\mathrm{RS}^{\bullet}\right)$, de cloro (Ex: $\mathrm{HOCl}$ ) etc. No grupo das espécies reativas estão contidos os radicais livres, compostos formados por átomos ligados entre si, que apresentam um elétron desemparelhado na última camada. Essas espécies são altamente reativas pois buscam estabilizarem-se, buscando, nas estruturas do organismo, os elétrons necessários à sua estabilização. Também no grupo das espécies reativas, estão contidas as espécies não radicais que, embora não apresentem elétrons desemparelhados na última camada,

1 Professor no Programa de Mestrado em Saúde e Envelhecimento da Faculdade de Medicina de Marília (FAMEMA) - Laboratório de Farmacologia. Endereço para correspondência: Rua Lourival Freire, 240. Bairro Fragata, CEP 17519050, Marília-SP. Email: agnaldochies@hotmail.com

2 Mestres no Programa de Mestrado em Saúde e Envelhecimento da Faculdade de Medicina de Marília (FAMEMA) Laboratório de Farmacologia. Emails (na ordem em que aparece): munhozgc@gmail.com; priscillabianca@outlook.com 
são altamente reativas. Espécies reativas não radicais podem ser transformadas em radicais no metabolismo, o que eleva substancialmente sua capacidade de reação com moléculas orgânicas e inorgânicas (VASCONCELOS et at, 2007).

Espécies reativas são geradas continuamente pelo metabolismo e em concentrações adequadas, participam de inúmeros processos fisiológicos. A eliminação de micro-organismos fagocitados se dá por meio da ação de elevadas concentrações de $\mathrm{O}_{2}^{\bullet}$ nos fagolisossomos dos neutrófilos. Espécies reativas também participam do processo de geração aeróbica de enérgica, na cadeia respiratória, são importantes mediadores das vias de sinalização intracelular etc. Entretanto, quando em excesso, essas espécies podem reagir com diferentes estruturas do organismo, entre as quais as macromoléculas como carboidratos, DNA, proteínas e lipídios, podendo levar a sérios danos celulares. Por essa razão, os organismos possuem sistemas antioxidantes que são responsáveis pela remoção de tais espécies reativas, controlando e reestabelecendo o chamado equilíbrio redox. Todavia, quando a produção de espécies reativas excede a capacidade das defesas antioxidantes em removê-las, tem-se uma condição fisiopatológica denominada estresse oxidativo que pode levar a danos celulares (ENGERS et al, 2011; BARBOSA et al, 2010).

As defesas antioxidantes do organismo dividem-se em: enzimáticas e não-enzimáticas. As defesas enzimáticas envolvem enzimas como superóxido desmutase, catalase, glutationa peroxidase e glutationa redutase. Estas enzimas atuam metabolizando as espécies reativas excendentes em produtos mais estáveis. Por outro lado, diversas substâncias contidas nos fluidos corporais conferem proteção oxidativa a estes, são as chamadas defesas antioxidantes não enzimáticas (BARBOSA et al, 2010).

O estresse oxidativo está envolvido em diversos processos fisiopatológicos, entre os quais a lesão por isquemia e reperfusão (CARACENI, 2005), doenças neurodegenerativas, inflamatórias etc. (CAO et al, 2014). O estresse oxidativo também está na base da disfunção endotelial, que é o ponto de partida de diversas doenças cardiovasculaares como hipertensão arterial sistêmica, doença ateromatosa etc. (AL GHOULEH, 2011). Além disso, desde os trabalhos pioneiros de Denham Harman publicados nos anos 50, a hipótese de que o envelhecimento seja resultados ao menos em parte das contínuas agressões oxidativas produzidas pelos radicais livres vem ganhando força (ENGERS et al, 2011).

Assim, a avaliação do grau de estresse oxidativo é essencial para a compreensão de diversos processos fisiologicos que mantêm a homestasia nas diversas fases do ciclo da vida, bem como para compreender os mecanismos que estão na gênese das principais doenças que acometem os seres humanos sobretudo no evelhecimento. Para essa avaliação, diversas técnicas foram propostas, desde as de custo elevado e mais complexas até as mais simples e baratas. Conhecer essas técnicas, sobretudo no que tange às suas potencialidades e limitações, pode ser útil na elaboração de projetos científicos relevantes e abrangentes. Além disso, pelo fato do entendimento do estresse oxidativo ultrapassar as fronteiras disciplinares, essas técnicas podem ser ferramentas de construção de projetos interdisciplinares. Neste sentido, o objetivo do presente trabalho é apresentar algumas técnicas simples voltadas ao estudo do estresse oxidativo, com enfoque no sistema cardiovascular, e fazer uma reflexão acerca de suas potencialidades e limitações. 


\section{Material e método}

A seguir, são apresentadas algumas técnicas que temos utilizado em modelos experimentais e em pesquisa com seres humanos.

\section{Reatividade vascular:}

Avaliamos os efeitos do estresse oxidativo sobre a função endotelial nos animais estudos através da análise das respostas de artérias e veias à agonistas como acetilcolina (ACh), noradrenalina, angiotensina II etc, em cuba de órgãos isolados (CHIES, 2017). Essa técnica, simples e barata, consiste na montagem de segmentos (anéis de $4 \mathrm{~mm}$ ) desses vasos em cubas de órgão isolado, contendo solução nutritiva. Nestas cubas, esses anéis são mantidos entre 2 hastes, sendo que um deles é afixada no fundo da cuba e a outra, a um transdutor isométrico de tensão. Considerando que as respostas relaxantes da ACh ocorrem pela liberação endotelial do óxido nítrico (NO), qualquer modificação dessas respostas pode indicar alterações na biodisponibilidade do NO. Da mesma forma, o endotélio também modula as respostas dos agonistas vasoconstritores, assim, modificações de resposta a esses agonistas podem indicar modificações da biodisponibilidade do NO. Como o NO é alvo dos radicais livres, modificações de reatividade vascular decorrentes da redução da biodisponibilidade do NO são indícios estresse oxidativo. Cabe ressaltar, que a participação do estresse oxidativo nas modificações de reatividade vascular precisa ser confirmada pelo emprego de "scavengers" ou de inibidores da síntese de radicais livres, coadministrados na cuba de órgãos.

\section{Quatificação dos produtos finais de peroxidação lipídica:}

Como foi mencionado anteriormente, espécies reativas reagem com lipídeos presentes nas diferentes estruturas células, bem como nos fluidos circulantes, promovendo a chamada lipoperoxidação. Com efeito, a quantificação dos produtos finais dessa lipoperoxidação é uma forma mensurar o grau de estresse oxidativo no meio estudado. Em nosso laboratório, quantificamos os produtos finais da peroxidação lipídica através da técnica do "Thiobarbituric Acid Reactive Substances" (TBARS), descrita em Wills (1966). Trata-se de uma técnica de fácil execução, barata e bastante aceita na literatura. Cabe destacar que o principal produto final da lipoperoxidação que reage com o TBA é o malondialdeído (MDA). Por conta disso, técnicas muito semelhantes ao TBARS são referidas como MDA. Vale esclarecer, contudo, que a nomenclatura MDA deve ser empregada caso a determinação seja feita em amostras contendo MDA purificado através técnicas específicas.

\section{Quatificação das defesas antioxidantes não enzimáticas:}

Existem métodos para avaliação destas defesas não enzimáticas presentes nos fluidos biológicos. Um destes métodos, é o Ferric Reducing Ability of Plasma (FRAP), descrito em Benzie e Strain (BENZIE, 1996), consiste nadeterminação da capacidade do plasma em reduzir o íon férrico $\left(\mathrm{Fe}^{+3}\right)$ a íon ferroso $\left(\mathrm{Fe}^{+2}\right)$ em $\mathrm{pH}$ ácido. Quanto maior for esta capacidade, maior o poder antioxidante do fluido biológico analisado. Dentre as substâncias que partici- 
pam dos mecanismos antioxidantes avaliados pelo FRAP destacam-se o ácido úrico e ácido ascórbico, que exercem respectivamente cerca de $60 \%$ e $20 \%$ da capacidade antioxidante avaliada. Outras substâncias também participam das defesas antioxidantes não enzimáticas determinada pelo FRAP, entre elas, a vitamina E, bilirrubinas e albumina. O FRAP fornece uma informação mais relevante do ponto de vista biológico do que a dosagem das substâncias que compôem as defesas antioxidantes não enzimáticas isoladamente. Isto porque o FRAP descreve o equilíbrio dinâmico entre pró-oxidantes e antioxidantes no plasma. Entretanto este método oferece algumas limitações pois nem todo antioxidante consegue reduzir o íon férrico e nem toda substância presente no plasma, capaz de reduzir o íon férrico, é considerado um antioxidante (VASCONCELOS et al, 2007). Além disso, o FRAP mede apenas defesas antioxidantes não-enzimáticas, não conseguindo portanto quantificar as enzimáticas. Também é considerado barato, reprodutível, simples e rápido, além de ser bem aceito pela literatura.

\section{Quantificação do nitrito e nitrato:}

O NO liberado pelos tecidos é rapidamente oxidado a nitrito e nitrato. Dessa forma, pode-se mensurar a biodisponibilidade do NO através da mensuração do pool nitrito/nitrato. Considerando que espécies reativas reagem com o NO, a determinação do nitrito/nitrato nos tecidos ou em fluidos biológicos pode sugerir o grau de estresse oxidativo nesses ambientes. Em nosso laboratório, fazemos a quantificação do nitrito pela técnica de Griess descrita em Giustarini et al (2008). Vale destacar, contudo, que para a determinação do pool nitrito/nitrato, as amostras são previamente tratadas com nitrato redutase de Aspergillus $(1 \mathrm{U} / \mathrm{ml})$, a fim de reduzir o nitrato a nitrito. Esta técnica é barata e de fácil execução, embora seu custo eleva-se um pouco por conta do emprego do nitrato redutase de Aspergillus. Por outro lado, a sensibilidade da técnica não é tão grande, uma vez que detecta concentrações de nitrito na faixa de micromolar. Com isso, seu emprego restringe-se a amostras com concentrações mais elevadas de nitrito/nitrato.

\section{Resultados/Conclusão}

Nos últimos seis anos temos empregado essas metodologias na investigação interdisciplinar de processos relacionados aos agravos cardiovasculares, tão comuns no envelhecimento. A partir dessa nossa experiência, ainda que breve, alguns pontos merecem ser destacados.

Primeiramente, as técnicas aqui apresentadas podem ser pontos de partida interessantes para a elaboração de projetos interdisciplinares. São técnicas que não dependem de um parque de equipamentos oneroso, pois podem ser realizadas com uma estrutura laboratorial básica, e o custo com o material de consumo é relativamente baixo. Com isso, projetos em fase inicial, propostos por grupos de pesquisadores sem experiência prévia de trabalho em conjunto e ainda sem financiamento, podem ser iniciados. Além disso, algumas dessas técnicas mensuram substâncias presentes em fluidos biológicos, como plasma, soro, leite materno etc. Nesse sentido, pesquisadores com experiência em modelos animais podem estabelecer colaborações com pesquisadores que estudam seres humanos. Por fim, são técnicas de simples 
execução, permitindo o envolvimento de alunos de iniciação científica e de pós-graduandos de áreas não diretamente relacionadas às ciências biomédicas. Isso deve ser ressaltado pois os programas de pós-graduação interdisciplinares com frequência recebem estudantes das diferentes áreas do saber.

Uma limitação que merece ser destacada é a possibilidade de fatores externos influenciarem os resultados obtidos por essas técnicas. Em relação à reatividade vascular, o estresse dos animais (CHIES et al, 2003), variações do ciclo circadiano dos animais (ULUOGLU et al, 2007) e a destreza cirúrgica daquele que monta as preparações podem influenciar os resultados. Assim, o cuidado com a padronização dos experimentos e com a randomização dos grupos experimentais é fundamental. Além disso, uma dieta rica ou pobre de antioxidantes pode influenciar as defesas antioxidantes não enzimáticas do organismo (BARBOSA et al, 2010), o que pode ter implicações tanto no TBARS quanto no FRAP. Nitratos presentes nos alimentos também podem interferir nas concentrações endógenas dessa substância (LI et al, 2016). Com isso, a padronização da dieta é fundamental para a confiabilidade dos resultados obtidos através da técnica de Griess, um desafio muito grande quando se trabalha com serem humanos.

Depois, o balanço redox pode modificar ao longo do curso de um determinado processo fisiopatológico. Recentemente observamos que os as respostas vasculares à noradrenalina e à angiotensina II, bem como os valores de FRAP, TBARS e nitrito/nitrato não estavam modificados em animais estudados 40 dias após indução de artrite. Contudo, modificações interessantes decorrentes do estresse oxidativo foram observadas nas fases mais precoces do modelo.

Por fim, toda e qualquer técnica que avalia o estresse oxidativo, inclusive as que foram mencionadas no presente trabalho, avaliam diferentes processos fisiopatológicos. Muitos desses processos fisiopatológicos estão inter-relacionam "em forma de peso e contrapeso". Como exemplo, elevações do estresse oxidativo que culminam com elevações de TBARS, comumente consomem defesas antioxidantes não-enzimáticas e reduzem o FRAP. Elevações do TBARS também são frequentemente acompanhadas por reduções de nitrito/nitrato ou por reduções das respostas relaxantes à ACh.

Enfim, pode-se concluir que a credibilidade do estudo eleva-se pelo cuidado na padronização das técnicas, pelo rigor do delineamento experimental e na medida em que os resultados obtidos por uma determinada técnica são corroborados por outras técnicas, que avaliam diferentes processos que determinam o balanço redox.

\section{Challenges related to the evaluation of oxidative stress in the aging process}

\section{Abstract}

Oxidative stress is defined as a pathophysiological condition in which the production of reactive species exceeds the ability of the body's antioxidant defenses to remove them. Assessing the degree of oxidative stress is essential for understanding the various physiological processes that maintain homostasy in the various phases of the life cycle. For this, several simple and inexpensive techniques can be employed. The present 
work proposes to present some techniques to study the study of oxidative stress, reflecting on its potentialities and limitations. It can be said that the credibility of the study is elevated by the careful standardization of the techniques, rigor of the experimental design and the confirmation of the results through different techniques that evaluate different processes that determine the redox balance.

Keywords: Antioxidant defenses; Oxidative stress; Endothelial function; Lipid peroxidation.

\section{Referencias}

AL GHOULEH, I.; KHOO, N.K.; KNAUS, U.G.; GRIENDLING, K.K.; TOUYZ, R.M.; THANNICKAL, V.J. et al. Oxidases and peroxidases in cardiovascular and lung disease: new concepts in reactive oxygen species signaling. Free Radic Biol Med. 2011;51(7):1271-88.

BARBOSA, K.B.F.; COSTA, N.M.B.; ALFENAS, R.D.C.G.; PAULA, S.O.; MININ, V.P.R.; BRESSAN, J. Oxidative Stress: Concept, implications and modulating factors. Revista de Nutrição. 2010;23(4):15.

BENZIE, I.F.; STRAIN, J.J. The ferric reducing ability of plasma (FRAP) as a measure of "antioxidant power": the FRAP assay. Anal Biochem. 1996;239(1):70-6.

CAO, S.S.; KAUFMAN, R.J. Endoplasmic reticulum stress and oxidative stress in cell fate decision and human disease. Antioxid Redox Signal. 2014;21(3):396-413.

CARACENI, P.; DOMENICALI, M.; VENDEMIALE, G.; GRATTAGLIANO, I.; PERTOSA, A.; NARDO, B. et al. The reduced tolerance of rat fatty liver to ischemia reperfusion is associated with mitochondrial oxidative injury. J Surg Res. 2005;124(2):160-8.

CHIES, A.B.; CORRÊA, F.M.; DE ANDRADE, C.R.; ROSA-E-SILVA, A.A.; PEREIRA, F.C.; DE OLIVEIRA, A.M. Vascular non-endothelial nitric oxide induced by swimming exercise stress in rats. Clin Exp Pharmacol Physiol. 2003;30(12):951-7.

CHIES, A.B.; DE OLIVEIRA, P.B.; ROSSIGNOLI, P.S., BAPTISTA, R.F.; DE LABIO, R.W.; PAYAO, S.L. Prostanoids counterbalance the synergism between endothelin-1 and angiotensin II in mesenteric veins of trained rats. Peptides. 2017;88:67-73.

ENGERS, V.K.; BEHLING, C.S.; FRIZZO, M.N. A influência do estresse oxidativo no processo de envelhecimento. Revista Contexto \& Saúde. 2011;10(20):10.

GIUSTARINI, D.; ROSSI, R.; MILZANI, A.; DALLE-DONNE, I. Nitrite and nitrate measurement by Griess reagent in human plasma: evaluation of interferences and standardization. Methods Enzymol. 2008;440:361-80.

LI, T.; LU, X.; SUN, Y.; YANG, X. Effects of spinach nitrate on insulin resistance, endothelial dysfunction markers and inflammation in mice with high-fat and high-fructose consumption. Food Nutr Res. 2016;60:32010.

ULUOGLU, C.; DURAKOGLUGIL, D.B.; KARASU, C.; OZBEY, G.; GUNES, A.; ZENGIL, H. The effect of experimental diabetes on the twenty-four-hour pattern of the vasodilator responses to acetylcholine and isoprenaline in the rat aorta. Chronobiol Int. 2007;24(6):1081-94.

VASCONCELOS, S.M.L.; GOULART, M.O.F.; MOURA, J.B.F.; MANFREDINI, V.; BENFATO, M.S.; KUBOTA, L.T. Espécies reativas de oxigênio e de nitrogênio, antioxidantes e marcadores de dano oxidativo em sangue humano: principais métodos analíticos para sua determinação. Quim Nova. 2007:1323-38.

WILLS, E. Mechanism of lipid peroxide formation in animal tissues. Biochem J 1966;99(5):10. 